\title{
AVALIAÇ̃̃O NUTRICIONAL DE RAÇÕES COMERCIAIS E SEMENTE DE GIRASSOL PARA PAPAGAIOS-VERDADEIROS (Amazona aestiva)
}

\author{
Nutricional evaluation of commercial foods and sunflower seed \\ for blue-fronted parrot (Amazona aestiva)
}

\author{
Carlos Eduardo do Prado Saad, Walter Motta Ferreira², Flávia Maria de Oliveira Borges ${ }^{3}$, \\ Leonardo Boscoli Lara ${ }^{4}$
}

\begin{abstract}
RESUMO
Neste experimento utilizou-se de 12 papagaios adultos, distribuídos em blocos ao acaso em seis tratamentos (T1-Ração extrusada para psitacídeos - A, T2 -Ração peletizada para psitacídeos -B, T3 - Ração extrusada para psitacídeos - C, T4 - Ração para cães linha prêmio; T5- Ração para cães linha econômica e T6 - Semente de Girassol), durante três períodos de colheita, totalizando seis repetições por tratamento. Avaliaram-se os valores de energia metabolizável aparente e verdadeira (EMA e EMV) e corrigidas pelo nitrogênio (EMAn e EMVn); coeficientes de digestibilidade dos nutrientes (energia bruta - EB, matéria seca - MS, matéria orgânica MO, fibra bruta - FB e extrato etéreo - EE), balanço de nitrogênio e proteína metabolizável das dietas testadas. As médias foram comparadas pelo teste SNK. Os resultados obtidos permitiram concluir que 1) os valores de EMA e EMV foram mais altos que EMAn e EMVn. 2) A semente de girassol apresentou a mais alta digestibilidade aparente e verdadeira da matéria seca e da matéria orgânica. 3) A digestibilidade dos lipídeos de todas as dietas foi alta (média de 92,62\%). 4) O balanço de nitrogênio (aparente e verdadeiro) foi positivo para todas as aves.
\end{abstract}

Termos para indexação: Digestibilidade, energia metabolizável, balanço de nitrogênio, psitacídeos.

\section{ABSTRACT}

In this experiment twelve adult parrots were used in a randomized block design distributed in six treatments (T1- Extruded food for psittacines-A, T2- Pellet food for psittacines-B, T3- Extruded food for psittacines-C, T4- Dog food premium line, T5- Dog food economic line and T6- Sunflower seed) during three harvest periods, in six replication for treatment. The values of apparent and true metabolizable energy (AME and TME) were determined and they were corrected by nitrogen (AMEn and TMEn), nutrients digestibility coefficients (GE-Gross Energy, OM-Organic Matter, CF-Crude Fiber and EE-Ether Extract), nitrogen balance and metabolizable protein. The data were analyzed by SNK test. The results allow to conclude that: 1) the values of AME e TME were higher than AMEn and TMEn; 2) the sunflower seeds showed the higher apparent and true digestibility of the dry and organic matter; 3 ) the lipids digestibility of all diets was high ( $92,62 \%$ in average) 4 ) The nitrogen balance (apparent and true) was positive for all parrots.

Index terms: Digestibility, metabolizable energy, nitrogen balance, psittacines.

(Recebido em 4 de novembro de 2005 e aprovado em 21 de agosto de 2006)

\section{INTRODUÇÃO}

Um dos entraves na criação de aves ornamentais ainda é a disponibilidade de rações comerciais. Grande parte dessas rações é importada, criando uma série de dificuldades para o criador nacional. Dessa forma, faz-se necessário o desenvolvimento de boas rações nacionais, que atendam economicamente ao criador e que, primariamente, atendam as necessidades nutricionais e as preferências de palatabilidade das aves que as consumirão (MACHADO \& SAAD, 2000).

O criador tem disponível no mercado basicamente três tipos de rações para aves silvestres: as fareladas, peletizadas e extrusadas. As rações fareladas apresentam uma série de desvantagens: permitem a seleção de partículas, acarretam grande desperdício por perdas no comedouro e, por serem pulverulentas, favorecem o aparecimento de doenças respiratórias (NUNES, 1998). As rações peletizadas contornam os problemas encontrados nas rações fareladas, mas o processo de peletização limita a inclusão de alguns princípios nutritivos, como óleos. A ração extrusada é a forma atualmente mais usual em rações comerciais de animais de companhia, como cães e gatos e, potencialmente, é a ração de futuro para aves ornamentais e silvestres. Rações extrusadas permitem uma alta inclusão

\footnotetext{
Zootecnista, D.Sc. em Nutrição de Animais Silvestres - AnimalNutri - Rua Dr. Armando Amaral, 122 - Padre Dehon - $37200-000$ - Lavras, MG eduardosaad@animalnutri.com.br; saadzoo@ufla.br

${ }^{2}$ Zootecnista, D.Sc., Professor Adjunto da Escola de Veterinária da Universidade Federal de Minas Gerais/UFMG - Av. Antônio Carlos, 6627 Pampulha - 30123-970 - Belo Horizonte, MG - waltermf@vet.ufmg.br

${ }^{3}$ Médica Veterinária, D.Sc. Professora Adjunta do Departamento de Zootecnia da Universidade Federal de Lavras/UFLA - Cx. P. 3037 - $37200-000$ Lavras, MG - borgesvet@ufla.br

${ }^{4}$ Médico Veterinário, D.Sc., Nutriara - Rua Jurutau, 1800 - Parque Industrial II - 86703-070 - Arapongas, PR - leoboscoli@gmail.com
} 
de lipídios sem danificar as propriedades físicas do produto. Outro aspecto positivo é a melhoria do valor energético do alimento ao aumentar a digestibilidade (DALE, 1996), sendo que este último parâmetro é um ponto importante para avaliação da qualidade dos alimentos.

Carciofi (1996) cita que os experimentos de digestibilidade foram desenvolvidos visando determinar a disponibilidade dos diversos nutrientes e que o objetivo de tais procedimentos é conhecer a utilização dos nutrientes presentes em um alimento, definindo desta forma seu valor nutricional.

Igualmente às criações de aves domésticas, um dos aspectos mais importantes para o sucesso de um programa alimentar em psitacídeos é o fornecimento energético, uma vez que o consumo voluntário de alimentos é regulado em função da quantidade de energia da dieta. Entretanto, pouco se sabe sobre o valor energético dos alimentos usualmente utilizados em dietas para papagaios.

Assim, objetivou-se com este trabalho determinar e comparar os coeficientes de digestibilidade da matéria seca, matéria orgânica, energia bruta, proteína, lipídeos e fibra de rações comerciais próprias para psitacídeos, rações de cães e da semente de girassol para psitacídeos; determinar a energia metabolizável aparente, aparente corrigida pelo nitrogênio, verdadeira, verdadeira corrigida pelo nitrogênio e proteína digestível das várias rações testadas e da semente de girassol; e avaliar a influência da forma de processamento da ração (peletizada versus extrusada) sobre a digestibilidade dos nutrientes para papagaios-verdadeiros.

\section{MATERIAL E MÉTODOS}

O experimento foi conduzido nas dependências do departamento de Zootecnia da Escola de Veterinária da Universidade Federal de Minas Gerais (UFMG), Foram utilizados 12 papagaios-verdadeiros (Amazona aestiva) adultos, de ambos os sexos, distribuídos ao acaso em seis tratamentos durante três períodos de colheita, totalizando seis repetições por tratamento (36 unidades experimentais). As aves foram alojadas individualmente em gaiolas metabólicas durante todo o período experimental.

Seis tratamentos foram testados: 1- Ração comercial extrusada para psitacídeos A; 2- Ração comercial peletizada para psitacídeos B; 3- Ração comercial extrusada para psitacídeos C; 4- Ração para cães linha prêmio; 5- Ração para cães linha econômica e 6- Semente de girassol. As rações para psitacídeos do tratamento um e dois (rações comerciais A e B) foram obtidas utilizando-se a mesma formulação, os mesmos ingredientes em quantidades idênticas, diferindo apenas no modo de processamento; extrusão e peletização, respectivamente. Já o tratamento três, refere-se a uma outra ração extrusada para psitacídeos, disponível comercialmente. O tratamento quatro é uma ração para cães de linha prêmio, enquanto que o tratamento cinco é uma ração para cães de linha econômica. Finalmente, o tratamento seis é composto apenas por sementes de girassol.

O consumo total de alimentos foi obtido registrando-se o peso inicial das rações oferecidas menos o peso final das sobras no comedouro e o desperdício nas bandejas coletoras. Para a avaliação da semente de girassol, foi considerada a relação $65,83 \%$ de semente e $34,17 \%$ de cascas, sendo essa porcentagem obtida descascando-se manualmente 500 gramas de sementes. Para o cálculo do consumo, todas as cascas encontradas na bandeja coletora foram desprezadas, considerandose como desperdício apenas as sementes inteiras. Os cálculos de consumo foram ajustados somente para semente descorticada.

Para a realização dos ensaios de digestibilidade, procedeu-se à colheita total de excreta, em três fases experimentais de cinco dias cada. Anteriormente a cada fase foi realizada uma adaptação de sete dias às dietas experimentais. Ao final do terceiro período experimental todas as aves foram colocadas em jejum durante 72 horas para a obtenção do fator de correção para a energia metabolizável verdadeira. As aves em jejum receberam uma solução de água e glicose (cinco gramas de glicose/ave/ dia), visando diminuir o estresse causado pelo não fornecimento de alimentos, conforme o recomendado por Macnab \& Blair (1988).

As análises das amostras das rações comerciais e semente de girassol (Tabela 1), bem como as excretas, foram realizadas no Laboratório de Nutrição Animal da Escola de Veterinária da UFMG e no laboratório de Nutrição do Instituto Mineiro de Agropecuária, segundo a metodologia da AOAC (CUNNIFF, 1995), para Matéria seca (MS), Matéria orgânica (MO), Proteína Bruta (PB), Fibra Bruta (FB), e Extrato Etéreo (EE). A energia Bruta (EB) foi realizada utilizando-se calorímetro adiabático PARR.

Os parâmetros avaliados foram: coeficientes de digestibilidade dos nutrientes (EB, MS, MO, FB, EE, PB), valores de energia metabolizável aparente (EMA), verdadeira (EMV), aparente corrigida pelo nitrogênio (EMAn) e verdadeira corrigida pelo nitrogênio (EMVn), balanço de nitrogênio (BN) e proteína metabolizável das dietas testadas. 
Os valores de energia metabolizável aparente, verdadeira, aparente corrigida pelo nitrogênio e verdadeira corrigida pelo nitrogênio, balanço de nitrogênio e proteína metabolizável das dietas testadas foram calculados segundo as fórmulas citadas por Borges (1999) e Rodrigues (2000).

O procedimento estatístico adotado foi o GLM do pacote estatístico SAS Institute (1995). O delineamento do experimento um foi em blocos ao acaso, com seis tratamentos $(\mathrm{t})$, três períodos experimentais $(\mathrm{k})$, e seis repetições (r). As médias tas foram comparadas pelo teste Student Newman Keuls para observação de todos os efeitos.

\section{RESULTADOS E DISCUSSÃO}

A semente de girassol apresentou os mais altos coeficientes de digestibilidade aparente (CDA) e verdadeira
(CDV), tanto da MS quanto da MO, diferindo $(\mathrm{P}<0,05)$ das demais dietas testadas (Tabela 2). A ração peletizada para psitacídeos B apresentou o menor CDA da MS e MO, juntamente com a ração para cães linha prêmio (MS) e econômica (MS e MO). Quanto ao CDV, a ração peletizada para psitacídeos B foi estatisticamente semelhante para a MS e MO $(\mathrm{P}>0,05)$ à ração para cães linha econômica, diferindo das demais dietas testadas $(\mathrm{P}<0,05)$.

As rações extrusadas para psitacídeos -A, extrusada para psitacídeos -C e ração para cães linha prêmio apresentaram CMA e CMV da MS e MO semelhantes estatisticamente $(\mathrm{P}>0,05)$. A ração extrusada para psitacídeos A apresentou maior CMA e CMV da MS e MO que a ração peletizada para psitacídeos -B. Considerando que as duas apresentavam a mesma composição básica, com os mesmos teores de ingredientes, diferindo apenas quanto ao processamento; extrusão e peletização,

TABELA 1 - Composição química (\%) e valores de energia bruta (kcal/g) das dietas experimentais ${ }^{1,2} 3$

\begin{tabular}{|c|c|c|c|c|c|c|}
\hline Dietas experimentais & MS & MO & EB & PB & FB & $\mathbf{E E}$ \\
\hline Ração extrusada para psitacídeos - A & 91,7 & 87,0 & 4560 & 18,0 & 2,3 & 7,2 \\
\hline Ração peletizada para psitacídeos -B & 90,4 & 85,2 & 4566 & 17,4 & 3,3 & 7,3 \\
\hline Ração extrusada para psitacídeos - C & 91,1 & 88,3 & 4842 & 23,3 & 0,9 & 8,6 \\
\hline Ração para cães linha prêmio & 92,4 & 87,4 & 5230 & 28,6 & 2,5 & 19,1 \\
\hline Ração para cães linha econômica & 91,3 & 85,4 & 4397 & 18,4 & 4,0 & 8,0 \\
\hline Semente de Girassol ${ }^{4}$ & 95,9 & 93,1 & 7643 & 24,8 & 2,9 & 57,8 \\
\hline
\end{tabular}

1- Dados expressos na base da matéria seca.

2- Análises realizadas no Laboratório de Nutrição da Escola de Veterinária da UFMG e no Laboratório de Nutrição do instituto Mineiro de Agropecuária.

3- $\mathrm{MS}=$ matéria seca, $\mathrm{MO}=$ matéria orgânica, $\mathrm{EB}=$ energia bruta, $\mathrm{PB}=$ proteína bruta, $\mathrm{FB}=$ fibra bruta, $\mathrm{EE}=$ extrato etéreo, $\mathrm{Cz}=$ cinzas, $\mathrm{ENN}=$ Extrativo não nitrogenado, $\mathrm{Ca}=$ Cálcio, $\mathrm{P}=$ Fósforo.

TABELA 2 - Coeficiente de digestibilidade aparente (CDA) e verdadeira (CDV), da matéria seca (MS) e da matéria orgânica (MO) das dietas experimentais $(\%)^{1}$.

\begin{tabular}{lcccc}
\hline \multirow{2}{*}{ Dietas experimentais } & \multicolumn{2}{c}{ CDA (\%) } & \multicolumn{2}{c}{ CDV (\%) } \\
\hline Ração extrusada para psitacídeos - A & MS & MO & MS & MO \\
Ração peletizada para psitacídeos -B & $70,45 \mathrm{bc}$ & $73,47 \mathrm{bc}$ & $73,92 \mathrm{~b}$ & $76,71 \mathrm{~b}$ \\
Ração extrusada para psitacídeos - C & $65,90 \mathrm{~d}$ & $69,33 \mathrm{~d}$ & $69,64 \mathrm{c}$ & $72,84 \mathrm{c}$ \\
Ração para cães linha prêmio & $73,23 \mathrm{~b}$ & $74,97 \mathrm{~b}$ & $76,13 \mathrm{~b}$ & $77,62 \mathrm{~b}$ \\
Ração para cães linha econômica & $69,08 \mathrm{~cd}$ & $72,67 \mathrm{bc}$ & $73,37 \mathrm{~b}$ & $76,69 \mathrm{~b}$ \\
Semente de Girassol & $67,77 \mathrm{~cd}$ & $71,07 \mathrm{~cd}$ & $70,14 \mathrm{c}$ & $73,31 \mathrm{c}$ \\
CV & $84,43 \mathrm{a}$ & $86,01 \mathrm{a}$ & $88,96 \mathrm{a}$ & $90,13 \mathrm{a}$ \\
\hline
\end{tabular}

1-Valores em uma mesma coluna, seguidos de letras distintas, diferem pelo teste de SNK $(\mathrm{P}<0,05)$. 
respectivamente, pode-se inferir que esta diferença de digestibilidade foi devido ao processo de extrusão, concordando com Dale (1996) que cita que o processo de extrusão melhora o valor do alimento por aumentar a digestibilidade.

Este aumento de digestibilidade da MS pode ser devido a uma gelatinização do amido, a uma melhora na digestibilidade da fibra e do extrato etéreo, por isso foram avaliados a digestibilidade do extrato etéreo (EE) e da fibra bruta (FB) das dietas experimentais, e os valores encontrados estão descritos na Tabela 3.

O CDA do EE da semente de girassol $(98,44 \%)$ foi o maior $(\mathrm{P}<0,05)$ de todas as dietas testadas, enquanto que o da ração para cães linha econômica, o menor estatisticamente $(85,08 \%)$. As rações extrusadas para psitacídeos $-\mathrm{A}$, ração peletizada para psitacídeos $-\mathrm{B}$, extrusada para psitacídeos - $\mathrm{C}$ e de cães linha prêmio apresentaram valores semelhantes $(\mathrm{P}>0,05)$ entre si $(92,49 \%$, $94,24 \%$ e $94,13 \%$, respectivamente), diferindo estatisticamente das demais.

Os dados encontrados neste experimento foram semelhantes aos encontrados por Kamwa (2002), que encontrou alto CDA dos lipídeos (87,19, 88,93, 89,17 e 90,89 $\%)$, trabalhando com dietas para papagaios-verdadeiros, com diferentes teores de lipídeos (6,03, 9,00, 11,20 e 13,65 $\%$ na MS, respectivamente).

Para o CDA da FB, pode-se observar que os maiores valores foram observados na semente de girassol $(63,77 \%)$ e na ração para cães linha prêmio $(58,09 \%)$. A ração para cães linha econômica apresentou um CDA da FB intermediário $(31,02 \%)$, diferindo das demais dietas testadas. A ração extrusada para psitacídeos - A apresentou um CDA da FB de 23,65\%, superior ao valor observado para ração peletizada para psitacídeos - B, onde se pode concluir que o processo de extrusão apresenta um efeito benéfico na digestibilidade da FB dos alimentos, concordando com Lukesova et al. (1996) que citam que a extrusão modifica a proporção de fibra insolúvel e solúvel da dieta, aumentando a quantidade dessa última.

Os coeficientes de metabolização aparente $\left(\mathrm{CMA}_{\mathbf{E}}\right)$, aparente corrigida pelo nitrogênio $\left(\mathrm{CMAn}_{\mathrm{E}}\right)$, verdadeira $\left(\mathrm{CMV}_{\mathbf{E}}\right)$ e verdadeira corrigida pelo nitrogênio $\left(\mathrm{CMVn}_{\mathbf{E}}\right)$, da energia bruta das dietas experimentais encontram-se na Tabela 4.

A semente de girassol foi, novamente, a dieta que apresentou maior coeficiente de metabolização da energia bruta $(\mathrm{P}<0,05)$, para todas as formas de estimativa $(92,23 \%$, 90,07\%, 94,07\% e 90,83\% para $\mathrm{CMA}_{\mathrm{E}} \mathrm{CMAn}_{\mathrm{E}}, \mathrm{CMV}_{\mathrm{E}}$ e $\mathrm{CMVn}_{\mathrm{E}}$, respectivamente). As rações extrusada para psitacídeos - A, extrusada para psitacídeos - C e de cães linha prêmio apresentaram coeficientes de metabolização da energia bruta semelhantes $(\mathrm{P}>0,05)$, diferindo das demais dietas. As rações peletizada para psitacídeos -B e de cães linha econômica foram estatisticamente semelhantes $(\mathrm{P}>0,05)$ e apresentaram os menores coeficientes de metabolização da energia bruta $(\mathrm{P}<0,05)$, quando comparadas às outras dietas avaliadas.

A ração extrusada para psitacídeos -A e peletizada para psitacídeos -B apresentavam a mesma composição e porcentagem de ingredientes e, conseqüentemente, valores de energia brutas semelhantes (4560 e $4566 \mathrm{Kcal} /$ $\mathrm{kg}$ de MS), então este incremento significativo na metabolização da energia $(3,75 \%, 2,92 \%, 3,57 \%$ e $2,85 \%$ para $\mathrm{CMA}_{\mathrm{E}}, \mathrm{CMAn}_{\mathrm{E}}, \mathrm{CMV}_{\mathrm{E}}$ e $\mathrm{CMVn} \mathrm{E}_{\mathrm{E}}$, respectivamente) pode ser atribuído exclusivamente ao processo de extrusão.

TABELA 3 - Coeficiente de digestibilidade aparente (CDA) do extrato etéreo (EE) e da fibra bruta (FB) das dietas experimentais $(\%)^{1}$.

\begin{tabular}{|c|c|c|}
\hline \multirow{2}{*}{ Dietas experimentais } & \multicolumn{2}{|c|}{ CDA (\%) } \\
\hline & EE & FB \\
\hline Ração extrusada para psitacídeos - A & $92,49 \mathrm{~b}$ & $23,65 \mathrm{c}$ \\
\hline Ração peletizada para psitacídeos -B & $91,33 \mathrm{~b}$ & $16,40 \mathrm{~d}$ \\
\hline Ração extrusada para psitacídeos - C & $94,24 \mathrm{~b}$ & $11,88 \mathrm{~d}$ \\
\hline Ração para cães linha prêmio & $94,13 \mathrm{~b}$ & $58,09 \mathrm{a}$ \\
\hline Ração para cães linha econômica & $85,08 \mathrm{c}$ & $31,02 \mathrm{~b}$ \\
\hline Semente de Girassol $^{2}$ & $98,44 \mathrm{a}$ & $63,77 \mathrm{a}$ \\
\hline $\mathrm{CV}$ & 2,29 & 15,95 \\
\hline
\end{tabular}

1- Valores em uma mesma coluna, seguidos de letras distintas, diferem pelo teste de SNK $(\mathrm{P}<0,05)$. 
Na Tabela 5 encontram-se, além dos valores de EMAn, também os valores de energia metabolizável aparente (EMA), verdadeira (EMV) e verdadeira corrigida (EMVn) das várias dietas testadas.

A EMA e EMAn apresentaram os menores valores energéticos que as EMV e EMVn, em todas as dietas. Isto porque a energia metabolizável aparente inclui uma porção energética referente às perdas metabólicas e endógenas das aves, subestimando a energia metabolizável real da dieta. Neste caso, a energia metabolizável verdadeira reflete com maior exatidão a energia metabolizável dos alimentos ingeridos, como pode ser constatado neste experimento.

Os valores EMAn e EMVn foram inferiores àqueles de EMA e EMV, coerentes com aqueles relatados por Borges (1999), encontrados em pintinhos e frangos de cortes, entretanto Rodrigues (2000) encontrou valores de EMA e EMV inferiores aos de EMAn e EMVn trabalhando com galos adultos.
Embora a digestibilidade da proteína bruta não tenha sido avaliada neste experimento, os dados de balanço de nitrogênio permitiram avaliar os coeficientes de metabolização aparente e verdadeiro da mesma, e se encontram descritos na Tabela 6 .

O balanço de nitrogênio (aparente e verdadeiro) foi positivo para todas as aves, o que sugere que as mesmas possam estar ainda depositando tecidos.

As rações extrusadas para psitacídeos $-\mathrm{C}$ e de cães linha econômica apresentaram valores de BN aparente e verdadeiro, numérica e estatisticamente iguais $(0,40 \mathrm{~g}$ e $0,55 \mathrm{~g}$ de $\mathrm{N}$, aparente e verdadeiro, respectivamente) $(\mathrm{P}>0,05)$, mas também não diferiram das sementes de Girassol ( $0,36 \mathrm{~g}$ de $\mathrm{N}$ retido) e da ração extrusada - A para psitacídeos $(0,22 \mathrm{~g}$ de $\mathrm{N}$ retido). Esta última por sua vez não foi significativamente diferente da ração peletizada para psitacídeos $-\mathrm{B}$.

TABELA 4 - Coeficientes de metabolização aparente $\left(\mathrm{CMA}_{\mathrm{E}}\right)$, aparente corrigida pelo nitrogênio $\left(\mathrm{CMAn}_{\mathrm{E}}\right)$, verdadeira $\left(\mathrm{CMV}_{\mathrm{E}}\right)$ e verdadeira corrigida pelo nitrogênio $\left(\mathrm{CMVn}_{\mathrm{E}}\right)$, da energia bruta $(\%)$ das dietas experimentais ${ }^{1}$.

\begin{tabular}{lcccc}
\hline Dietas experimentais & $\mathbf{C M A}_{\mathbf{E}}$ & $\mathbf{C M A n}_{\mathbf{E}}$ & $\mathbf{C M V}_{\mathbf{E}}$ & $\mathbf{C M V n}_{\mathbf{E}}$ \\
\hline Ração extrusada para psitacídeos - A & $75,78 \mathrm{~b}$ & $73,91 \mathrm{~b}$ & $78,14 \mathrm{~b}$ & $74,89 \mathrm{~b}$ \\
Ração peletizada para psitacídeos -B & $72,03 \mathrm{c}$ & $70,99 \mathrm{c}$ & $74,57 \mathrm{c}$ & $72,04 \mathrm{c}$ \\
Ração extrusada para psitacídeos - C & $77,30 \mathrm{~b}$ & $74,93 \mathrm{~b}$ & $79,16 \mathrm{~b}$ & $75,70 \mathrm{~b}$ \\
Ração para cães linha prêmio & $77,41 \mathrm{~b}$ & $76,03 \mathrm{~b}$ & $79,95 \mathrm{~b}$ & $77,08 \mathrm{~b}$ \\
Ração para cães linha econômica & $71,02 \mathrm{c}$ & $68,51 \mathrm{c}$ & $72,68 \mathrm{c}$ & $69,20 \mathrm{~d}$ \\
Semente de Girassol & $92,23 \mathrm{a}$ & $90,07 \mathrm{a}$ & $94,07 \mathrm{a}$ & $90,83 \mathrm{a}$ \\
\hline CV & 3,03 & 3,44 & 2,88 & 3,85 \\
\hline
\end{tabular}

1- Valores em uma mesma coluna, seguidos de letras distintas, diferem pelo teste de $\mathrm{SNK}(\mathrm{P}<0,05)$.

TABELA 5 - Valores de energia metabolizável aparente (EMA), aparente corrigida pelo nitrogênio (EMAn), verdadeira (EMV) e verdadeira corrigida pelo nitrogênio (EMVn), em Kcal $/ \mathrm{kg}$ de MS, das dietas experimentais.

\begin{tabular}{|c|c|c|c|c|}
\hline Dietas experimentais & EMA & EMAn & EMV & EMVn \\
\hline Ração extrusada para psitacídeos - A & $3456,0 \pm 35,5$ & $3370,5 \pm 44,0$ & $3563,5 \pm 41,3$ & $3415,0 \pm 34,4$ \\
\hline Ração peletizada para psitacídeos -B & $3288,8 \pm 131,6$ & $3241,5 \pm 136,4$ & $3404,8 \pm 154,1$ & $3289,4 \pm 112,7$ \\
\hline Ração extrusada para psitacídeos - C & $3743,0 \pm 131,0$ & $3628,1 \pm 106,1$ & $3832,9 \pm 157,9$ & $3665,3 \pm 97,9$ \\
\hline Ração para cães linha prêmio & $4048,7 \pm 75,4$ & $3976,5 \pm 85,2$ & $4181,6 \pm 93,0$ & $4031,4 \pm 64,0$ \\
\hline Ração para c & $3122,5 \pm 158,0$ & $3012,4 \pm 158,9$ & $3195,8 \pm 178,1$ & $3042,7 \pm 139,9$ \\
\hline Semente de G & $7049,6 \pm 87,3$ & $6884,2 \pm 65,8$ & $7189,7 \pm 114,9$ & $6942,0 \pm 59,2$ \\
\hline Média & $4118,1 \pm 1349$ & $4008,1 \pm 1365$ & $4217,3 \pm 1379$ & $4064,3 \pm 1449$ \\
\hline
\end{tabular}


TABELA 6 - Balanço de nitrogênio aparente (BNA) e verdadeiro (BNV) em gramas por ave/dia e coeficiente de metabolização aparente $\left(\mathrm{CMA}_{\mathrm{PB}}\right)$, e verdadeiro $\left(\mathrm{CMV}_{\mathrm{PB}}\right)$ da proteína $(\%)$ das dietas experimentais ${ }^{1}$.

\begin{tabular}{lcccc}
\hline Dietas experimentais & BNA $(\mathbf{g})$ & $\mathbf{B N V}(\mathbf{g})$ & $\mathbf{C M A}_{\mathbf{P B}}(\boldsymbol{\%})$ & $\mathbf{C M V}_{\mathbf{P B}}(\boldsymbol{\%})$ \\
\hline Ração extrusada para psitacídeos - A & $0,22 \mathrm{ab}$ & $0,38 \mathrm{ab}$ & $36,07 \mathrm{~b}$ & $62,73 \mathrm{~b}$ \\
Ração peletizada para psitacídeos -B & $0,13 \mathrm{~b}$ & $0,29 \mathrm{~b}$ & $20,65 \mathrm{c}$ & $50,42 \mathrm{c}$ \\
Ração extrusada para psitacídeos - C & $0,40 \mathrm{a}$ & $0,55 \mathrm{a}$ & $37,52 \mathrm{~b}$ & $54,77 \mathrm{bc}$ \\
Ração para cães linha prêmio & $0,15 \mathrm{~b}$ & $0,31 \mathrm{~b}$ & $19,17 \mathrm{c}$ & $39,91 \mathrm{~d}$ \\
Ração para cães linha econômica & $0,40 \mathrm{a}$ & $0,55 \mathrm{a}$ & $45,52 \mathrm{ab}$ & $63,32 \mathrm{~b}$ \\
Semente de Girassol & $0,36 \mathrm{a}$ & $0,51 \mathrm{a}$ & $52,03 \mathrm{a}$ & $77,93 \mathrm{a}$ \\
\hline $\mathrm{CV}$ & 48,67 & 48,82 & 24,98 & 13,48 \\
\hline
\end{tabular}

1- Valores em uma mesma coluna, seguidos de letras distintas, diferem pelo teste de $\mathrm{SNK}(\mathrm{P}<0,05)$.

A semente de girassol apresentou os maiores valores $(\mathrm{P}<0,05)$ de CMAPB e CMVPB, entretanto para CMAPB foi semelhante à ração para cães linha econômica $(\mathrm{P}>0,05)$. Para CMVPB, as rações extrusada para psitacídeos - A e extrusada para psitacídeos -C também foram estatisticamente iguais entre si. A ração para cães linha prêmio foi a dieta que apresentou menor CMVPB, diferindo significativamente de todas as demais.

Embora a técnica oficial para avaliar a digestibilidade da proteína seja através de medições do ácido úrico excretado, acredita-se que o CMVPB possa apresentar altas correlações com esta medida. Isto porque esta medida foi obtida subtraindo-se do nitrogênio consumido o nitrogênio excretado mais o nitrogênio obtido das aves em jejum. Partindo-se do princípio que as aves em jejum apresentavam a mesma excreção de ácido úrico, e que este, por diferença, foi subtraído para obtenção do coeficiente mencionado, pode-se supor que a medida de CMVPB aproxima-se muito do coeficiente de digestibilidade protéica.

Sendo assim poder-se-ia conjecturar que a digestibilidade da proteína do girassol é alta, enquanto que a digestibilidade da proteína da ração para cães linha prêmio é relativamente baixa. Entretanto, para que se confirme esta relação são necessários trabalhos futuros com a medida do ácido úrico e realização de correlações entre as duas metodologias.

Igualmente a Carciofi (1996), e devido ao exposto acima, não foi possível determinar se a menor retenção de nitrogênio da ração para cães linha prêmio foi ocasionada por uma menor digestibilidade da proteína consumida, por um pior equilíbrio entre os aminoácidos ingeridos, por características intrínsecas do indivíduo em estudo ou pela interação destes fatores. Entretanto, do mesmo modo que o referido autor, acredita-se que o equilíbrio de aminoácidos e a digestibilidade devam estar influenciando os resultados observados.

\section{CONCLUSÕES}

Os resultados obtidos neste estudo permitem as seguintes conclusões: 1) as medidas de EMA e EMV foram mais altas que EMAn e EMVn. 2) a semente de girassol apresentou as mais altas digestibilidades aparente e verdadeira da matéria seca e da matéria orgânica. 3) devido ao fato da ração extrusada para psitacídeos -A apresentar maior digestibilidade aparente e verdadeira da MS e MO que a ração peletizada para psitacídeos $-\mathrm{B}$, pode-se inferir que o processo de extrusão foi responsável por este aumento de digestibilidade. 4) a digestibilidade dos lipídeos de todas as dietas foi alta (média de 92,62\%). 5) a ração extrusada para psitacídeos -A apresentou uma digestibilidade aparente da fibra bruta $23,65 \%$ superior ao valor observado para ração peletizada para psitacídeos $\mathrm{B}$, donde pode-se concluir que o processo de extrusão apresenta um efeito benéfico na digestibilidade deste componente e 6) O balanço de nitrogênio (aparente e verdadeiro) foi positivo para todas as aves.

\section{REFERÊNCIAS BIBLIOGRÁFICAS}

BORGES, F. O. B. Valores energéticos e aminoácidos digestíveis do grão de trigo e seus subprodutos para aves. 1999. 118 f. Tese (Doutorado em Ciência Animal) Universidade Federal de Minas Gerais, Belo Horizonte, 1999.

CARCIOFI, A. C. Avaliação de dieta à base de sementes e frutas para papagaios (Amazona sp): determinações da seletividade dos alimentos, consumo, composição nutricional, digestibilidade e energia metabolizável. 1996. 104 f. Dissertação (Mestrado) - Universidade de São Paulo, São Paulo, 1996. 
CUNNIFF, P. (Ed.) Official methods of analysis of AOAC International. 16. ed. Arlington: AOAC International, 1995. v. 1.

DALE, N. Improving nutrient utilization by ingredient and dietary modification. Word Poultry, [S.1.], v. 12, n. 2, p. 33, 1996.

KAMWA, E. B. Níveis crescentes de lípase exógena em dietas para papagaios verdeairos (Amazona aestiva) com diferentes taxas de inclusão de óleo de girassol. 2002. 58 f. Tese (Doutorado em Ciência Animal) Universidade Federal de Minas Gerais, Belo Horizonte, 2002.

LUKESOVA, P.; PRIHODA, J.; MACKOVA, B. Changes in dietary fibre characteristics after the extrusion of cereals. Potravinarske Vedy, [S.1.], v. 14, n. 1, p. 13-24, 1996.
MACHADO, P. A. R.; SAAD, C. E. P. O futuro das rações para aves ornamentais e silvestres no Brasil. Aves Revista Sul Americana de Ornitofilia, Belo Horizonte, v. 3, p. 37-40, 2000.

McNAB, J. M.; BLAIR, J. C. Modified assay for true and apparent metabolisable energy based on tube feeding. British Poultry Science, London, v. 29, n. 4, p. 697-707, 1988.

NUNES, I. J. Nutrição animal básica. 2. ed. Belo Horizonte: FEP-MVZ, 1998. 388 p.

RODRIGUES, P. B. Digestibilidade de nutrientes e valores energéticos de alguns alimentos para aves. 2000. $185 \mathrm{f}$. Tese (Doutorado em Zootecnia) - Universidade Federal de Viçosa, Viçosa, 2000.

SAS INSTITUTE. SAS user's guide: statistics. Cary, 1995. $956 \mathrm{p}$. 